\title{
REMOÇÃO DA TOXICIDADE DO EFLUENTE DA DEGRADAÇÃO DE FENOL EM SISTEMA COMBINADO ANAERÓBIO-AERÓBIO UTILIZANDO TESTE DE TOXICIDADE
}

\author{
Samara Victor Ferreira*, Edson Aparecido Abdul Nour, Fernando Pena Candello.
}

\begin{abstract}
Resumo
Esta pesquisa visa avaliar o resíduo final gerado por um reator combinado tratando esgoto sanitário contendo fenol por meio de ensaios. O sistema consiste na degradação de elevadas concentrações de fenol utilizando esgoto sanitário como co-substrato, em sistema combinado anaeróbio-aeróbio, constituído de filtro anaeróbio (FA) seguido de biofiltro aerado submerso (BAS) e decantador secundário (DS), operado de forma a alcançar a concentração limite para inibição da biomassa anaeróbia, e posterior adoção da recirculação interna do efluente tratado para alcançar a reversão da inibição desta biomassa. Desta forma, foi desenvolvido um sistema compacto de alta taxa para a degradação de compostos tóxicos como o fenol, aplicando a recirculação interna do efluente tratado como solução para amenizar seus efeitos tóxicos sobre a biomassa anaeróbia, de forma a produzir um efluente com qualidade suficiente para ser lançado em corpos d'água, ou seja, que atinja os padrões de lançamento da legislação vigente. A qualidade do efluente final para avaliação do impacto ambiental será por meio de testes de toxicidade, utilizando a espécie Daphnia similis.
\end{abstract}

\section{Palavras-chave:}

Fenol, Daphnia similis, toxicidade.

\section{Introdução}

Os testes de toxicidade em ecossistemas aquáticos ou no sedimento, utilizando organismos vivos padronizados são imprescindíveis para avaliar o potencial poluidor de diversas substâncias presentes no meio, em concentrações muitas vezes inferiores aos limites de detecção de metodologias analíticas.

O fenol é um composto orgânico proveniente tanto de fontes naturais, como também artificiais, sendo muito utilizado em diversas indústrias. Durante muito tempo foi utilizado como anti-séptico por ter poder desinfetante e apresentar alta toxicidade.

Para este projeto de iniciação científica, os Testes de Toxicidade foram a ferramenta principal para avaliação da qualidade e desempenho do sistema de tratamento, objetivando avaliar o grau de remoção obtido pelo sistema quanto a uma variável muito importante na avaliação de seu potencial de dano ao meio ambiente.

\section{Resultados e Discussão}

O presente projeto teve duração de sete meses por motivo de início de estágio.

$\mathrm{O}$ teste de toxicidade aguda (CE50/48h) seguiu a norma técnica NBR 12713 (2009) ABNT. Aqui serão apresentados dados e resultados obtidos segundo a operação do sistema sob as seguintes condições: TDH de 17 horas, concentração de $200 \mathrm{mg}$ fenol/L no efluente bruto. Foram realizados dois ensaios de sensibilidade com Daphnia similis.

O primeiro foi considerado um ensaio preliminar, pois a concentração tóxica aos organismos não era conhecida, sem parâmetros para a diluição. Na amostra de esgoto bruto concentrado $6,25 \%$ houve a imobilidade de 1 indivíduo entre 20, o que foi considerado o ciclo natural do organismo, portanto não houve a necessidade de análises posteriores. Na amostra de DS, com imobilidade de 3 indivíduos, discutiu-se a possibilidade de contaminação, já que a etapa anterior a ele (BAS) obteve $0 \%$ de mortalidade. As amostras que apresentaram $0 \%$ de mortalidade (esgoto bruto concentrado 12,5\%; $25 \%$ e
$50 \%$ e BAS) garantiram a sobrevivência dos organismos, logo não houve necessidade de análises físico-químicas finais. Essas análises também não foram feitas nos experimentos que obtiveram $100 \%$ de mortalidade, pois os parâmetros inicias já eram críticos aos organismos.

No segundo ensaio, apenas diluições do esgoto bruto e o BAS foram analisados. Nas amostras de BAS e de esgoto bruto com concentração de $10 \%$ houve a morte de apenas 1 indivíduo entre 20, ciclo natural do organismo. Com relação ao esgoto bruto, as amostras mais concentradas que não causaram imobilidade maior que $50 \%$ aos organismos foram a de concentração $12 \%$ e $14 \%$, as quais tiveram respectivamente imobilidade de $20 \%$ e $25 \%$. Em ambas foram lidos os parâmetros finais, os quais provaram que as condições das amostras ainda eram adequadas à sobrevivência da espécie Daphnia similis. Portanto, o fenol foi o causador da imobilidade dos organismos.

\section{Conclusões}

Com relação ao primeiro experimento realizado não foi possível calcular a CE-50, portanto este foi chamado de ensaio preliminar. Pode-se concluir que a CE-50 está acima de $50 \%$ de diluição da amostra e que houve ausência de toxicidade aguda.

O segundo teste nos fornece a concentração teórica de fenol, $200 \mathrm{mg} / \mathrm{L}$, pois experimentalmente os valores ultrapassaram os limites de quantificação.

Também se pode calcular por ele a CE-50 e quanto menor o valor dessa porcentagem mais tóxica é a amostra. No ensaio com esgoto bruto a CE-50 é 15,55\% e a amostra de BAS não apresenta toxicidade aguda.

ABNT - Associação Brasileira de Normas Técnicas (2009). Ecotoxicologia aquática - toxicidade aguda de ensaio com Daphnia spp. (Cladocera, Crustácea). NBR 12713. Rio de Janeiro. Brasil

U.S.EPA. Toxicological Review of Phenol. Washington D.C. (EPA-635-R02-006). 213 p. 2002.

VON SPERLING, M. Princípios do tratamento biológico de águas residuárias: Introdução à qualidade das águas e ao tratamento de esgotos. Belo Horizonte: Departamento de Engenharia Sanitária e Ambiental - UFMG, v.1, 452p., 2005. 